\title{
Effect of educational guidelines based on health belief model regarding testicular cancer knowledge, practice and beliefs among male nursing students
}

\author{
Samira E. El Mezayen ${ }^{1}$, Seham A. Abd El-Hay*2 \\ ${ }^{1}$ Community Health Nursing, Faculty of Nursing, Tanta University, Egypt \\ ${ }^{2}$ Medical \& Surgical Nursing, Faculty of Nursing, Tanta University, Egypt
}

Received: December 9, 2018

Accepted: June 4, 2019

Online Published: June 19, 2019

DOI: $10.5430 /$ cns.v7n3p27

URL: https://doi.org/10.5430/cns.v7n3p27

\begin{abstract}
Background: Testicular cancer is considered one of the most important health threats in a young men's life. However, it is easily detected at an early stage by periodic testicular self-examination (TSE). Awareness of testicular cancer and TSE among university students is very important to aid in early detection and improve health belief. Aim: This study was conducted to evaluate the effect of educational guidelines based on health belief model regarding testicular cancer knowledge, practice and beliefs among male nursing students.

Methods: Design: A quasi experimental study design was used and data were collected from Faculty of Nursing, Tanta University. Sample: Proportion stratified random sample of 160 from 500 undergraduate male nursing students were selected as following: about one third of male students from total number of them in different years in the faculty (first, second, third and fourth year). Tools: Three tools were used for data collection. Tool (I): Structure questionnaire sheet to assess students knowledge regarding testicular cancer; Tool (II): Self-reported practices regarding TSE; and Tool (III): Beliefs of students regarding testicular cancer and TSE by Using Health Belief Model (HBM).

Results: The results of this study showed that there were significant improvements among students 'knowledge and selfreported practice about testicular cancer \& TSE post 3-month and 6-month from educational guidelines. Furthermore, there was improvement in the positive health beliefs about behavioral changes regarding prevention of testicular cancer was observed post 6-month from implementing educational guidelines.

Conclusion and Recommendation: These results indicated that educational guidelines about testicular cancer and TSE training are effective in improving knowledge, practice and health belief of young men, but TSE training should be repeated periodically for better efficacy. University faculties should create knowledge and organize workshops about TSE for students and encourage them to perform it regularly.
\end{abstract}

Key Words: Testicular cancer, Testicular self-examination, Manifestation, Diagnosis, Prevention and health beliefs model

\section{INTRODUCTION}

Testicular cancer is one of the most frequently occurring cancers among young men that are aged from 15-44 years old. ${ }^{[1-9]}$ Recent trends are suggested that there is an increase in testicular cancers as a diagnosis throughout the world for about $20 \%$ and $14 \%$ mortality rate are also occurring

\footnotetext{
*Correspondence: Seham A. Abd El-Hay; Email: drsehamahmed@yahoo.com, seham.abdelgawad@nursing.tanta.edu.eg; Address: Medical \& Surgical Nursing, Faculty of Nursing, Tanta University, Egypt.
} 
at this age, for this reason testicular cancer is considered one of the most important health threats in a young men's life.$^{[10,11]}$ According to the American Cancer Society's 2017, it is estimated that about 8,850 men in the United States were diagnosed with testicular cancer. For men aged 15-44 years, it is the most commonly diagnosed cancer and about 410 deaths from this disease were occurred at this year. ${ }^{[12-16]}$ In Egypt, National Cancer Institute was reported that the relative incidence of testicular cancer rate at the year of 2016 was 0.5 per $100,000 .^{[13]}$

Testicular cancer is a malignant tumor of the male sex organ (testicle) in the reproductive system that is normally produces testosterone hormone, where testicular cells become abnormal in one or both testicles. Symptoms of testicular cancer may include a lump in the testicle, swelling, pain, and feeling of heaviness, back pain and sudden collection of fluid in the scrotum. ${ }^{[17]}$ The exact cause of testicular cancer is unknown but risk factors include undescended testicles, family history and personal history. Other risk factors include race, ethnicity, HIV infection, and occupational hazards (e.g., exposure to chemicals). Some testicular tumors tend to metastasize early, spreading from the testis to the other organs especially the lungs. ${ }^{[18]}$ More than $90 \%$ of patients testicular cancer are cured with surgery, radiotherapy and chemotherapy alone or combination of them. ${ }^{[19,20]}$

World Health Organization 2018 reported that any type of cancer can be controlled through implementation of strategies for prevention, early detection and management of the patient. Testicular cancer is highly treatable disease and has a good prognosis, especially if it detected early. ${ }^{[21]}$ Prevention strategies for testicular cancer mainly depend on awareness about risk factors, manifestations and performing regular testicular self-examination (TSE) which is extremely important for early detection and preventing extension of the tumor stage, particularly with the nonseminomas and rapidly growing testicular tumors. ${ }^{[22,23]}$ The American Cancer Society recommended that TSE is an important part of the routine cancer related prevention because it is a simple and cost-effective procedure, it is necessary to be recommended for all men monthly after puberty, in addition to increasing knowledge about testicular cancer. ${ }^{[24]}$

TSE refers to the procedure by which a man checks the appearance as well as the consistency of testicles to observe and detect any changes that may occur such as lumps or swelling. ${ }^{[25]}$ TSE performed during or after a warm shower, which relaxes the scrotum. It is normal for one testicle to be slightly larger or hang slightly lower than the other, but other signs may be abnormal, awareness about TSE can help to facilitate early detection. ${ }^{[26]}$ In academic environments the majority of male students had not knowledge about testicular cancer and TSE, in addition to negative health beliefs about behavioral changes, so health educational guidelines is important recommendations for these students, to increase their knowledge about causes and common early symptoms of testicular cancer, and be familiar with performance of TSE. ${ }^{[27,28]}$

Health beliefs are the individual's perception of susceptibility and severity of the illness, the benefits of carrying out the behavior and cues to action. A later addition to the health belief was self-efficacy. Self-efficacy is the confidence in completing tasks and reaching goals, individuals must feel threatened by current behavioral patterns and believe that a specific change will result in a valued outcome. ${ }^{[29,30]}$ It seems that men have poor health seeking behavior and beliefs regarding TSE and are unwilling to seek cancer screening tests as routine medical checks. This considers a major concern for the timely detection and treatment of testicular cancer, to alleviate this problem, cancer scholars advocate proper information about the disease and educational guidelines must be organized among men. ${ }^{[31]}$

Lack of knowledge about the risks and warning signs of male students' specific diseases, such as testicular cancer is serious health problems ${ }^{[28]}$ so educational guidelines about testicular cancer such as anatomy of testes as normal shape and texture, in addition to informing regarding causes, risk factors and manifestation and performance of TSE must be a critical component in early detection and improving positive health beliefs about behavioral changes regarding prevention of testicular cancer. ${ }^{[8,27]}$ Therefore this study was planned to evaluate the effect of educational guidelines based on health belief model regarding testicular cancer knowledge, practice and beliefs among male nursing students.

\subsection{Significance of the study}

Although the worldwide increasing incidence of testicular cancer has been recognized, the reports of various surveys revealed that knowledge, practice and health beliefs about testicular cancer and TSE among adolescent and young adult males remained poor. ${ }^{[32]}$ In the same time, there were many screening methods for breast cancer among women has been discussed in more previous studies but on the other hand little studies have been performed for education about testicular cancer and TSE especially among university students in Egypt ${ }^{[33]}$ so it is necessary to conduct our research to improve male undergraduate nursing students awareness, performance and positive health beliefs regarding testicular cancer and TSE training because of they will be the main source of information for other people in the community. 


\subsection{Aim of the study}

Evaluate the effect of educational guidelines based on health belief model regarding testicular cancer knowledge, practice and beliefs among male nursing students.

\subsection{Research hypothesis}

- Knowledge mean scores of male nursing students regarding testicular cancer and TSE are expected to be improved post implementation of educational guidelines.

- Practice of male nursing students for TSE is expected to be improved post implementation of educational guidelines.

- Health belief of male nursing students about testicular cancer and TSE is expected to be improved post implementation of educational guidelines.

\section{SUBJECTS AND METHOD}

\subsection{Research design}

A quasi-experimental study design was used in the present research.

\subsection{Setting}

The study was carried out at the Faculty of Nursing of Tanta University, Egypt.

\subsection{Subjects}

Proportion stratified random sample of 160 undergraduate male nursing students from the above mentioned setting was included in the study. The sample size was estimated by using Epi Info Software Statistical package created by World Health Organization and Center for Disease Control and Prevention, Atlanta, Georgia, USA version 2002 through the following parameters; The sample size was estimated by using Epi Info 7 Statistical Program through the following parameters; Total target population size $=500$ students, confidence level $=99.9 \%$, expected frequency $=50 \%$, accepted error $=5 \%$ and confidence co efficient $=95 \%$. The accepted sample size was 160 students divided as the following; one third of male students from total number of the faculty students in different year (first, second, third and fourth) at 2017-2018 accademic year.

\subsection{Tools of data collections}

Three tools were used to collect the data for this study. These tools aimed to evaluate the effect of educational guidelines based on health belief model regarding testicular cancer knowledge, practice and beliefs among male nursing students.

Published by Sciedu Press

\subsubsection{Tool (I): Structure Questionnaire Sheet}

It was comprised of three parts:

Part (1): Socio-demographic characteristics of students: which includes; students' code, age, academic years, family history of testicular cancer and students smoking habits.

Part (2): Students' knowledge regarding testicular cancer:

It was developed by the researchers after reviewing of the related literature ${ }^{[31-35]}$ to gather male students' knowledge pre, 3-month and 6-month post implementation of educational guidelines. It was included the following:

- Students' knowledge about risk factors, causes and manifestation of testicular cancer which consisted of 24 questions.

- Students' knowledge about diagnostics measures , treatment and prevention of testicular cancer which consisted of 18 questions it included; history and physical examination, diagnostic methods, types of testicular cancer treatment, healthy diet, physical activity, controlling smoking, stress and environmental toxins.

Part (3): Students' knowledge about TSE (12) questions which included: how to perform TSE, started age for examination, uses of self-examination to prevent cancer, time of TSE, warning signs of testicular cancer.

\section{The scoring system of the knowledge}

Two level of scoring for questions were used as the following:

-“Correct answer" scored (1).

-"Don't know or incorrect answer" scored (0).

The total scoring systems of students' knowledge were as the following: part (2-A) was 24 points, part (2-B) was 18 points and part (3) was 12 points.

\subsubsection{Tool (II): Students' self-reported practices regard- ing TSE}

This tool was developed by the researchers after reviewing relevant literature ${ }^{[31-35]}$ to evaluate male students' practice pre, 3-month and 6-month post implementation of educational guidelines regarding TSE, it included 14 steps as: preparation before procedure, equipment, monthly time, ideal environment for performance procedure, assessment of abnormal signs of testicular cancer.

The scoring system for students' practice was calculated as the following:

-"Done practices" take (1).

-“Not done practices" take (0).

The total scoring systems of students' self-reported practice 
was 14 points.

\subsubsection{Tool (III): Beliefs of students regarding testicular cancer and TSE by Using Health Belief Model (HBM)}

Adapted Health belief model developed by Rosenstock $1974^{[36]}$ and Janz \& Becker $1984^{[37]}$ and modified by the researchers based on literature review. ${ }^{[38-40]}$ It was consisted of five subscales as following: perceived susceptibility, perceived seriousness, perceived benefit and health motivation, perceived barriers, perceived self-efficacy. Scoring system: Questionnaire consisted of 37 items used three-point Likerttype scale instead of five point Likert-scale with the following responses: 3 = agree, 2 = netural, $1=$ disagree to measure perceptions of students behavior related to testicular cancer and TSE. Higher scores on the susceptibility, seriousness, health motivation, benefits, and self-efficacy subscales indicate a positive situation, while higher scores on the barriers subscale indicate a negative situation since those with a high level of perceived barriers would not do testicular cancer screening.

Scoring system; each item of Health Belief Model was scored as following: Susceptibility had minimum score of (5) and maximum score of (15). Seriousness had minimum score of (10) and maximum score of (30). Benefit had minimum score of (9) and maximum score of (27). Barriers had minimum score of (9) and maximum score of (27). Self-efficacy had minimum score of (4) and maximum score of (12).

\subsection{Ethical consideration}

All students were informed about the aim of the study and their rights according to research ethics that they were free to decide whether or not they would participate in the study. Then written informed consent was obtained from each student who agreed to participate in the study. Confidentiality and privacy was taken into consideration regarding data collection. A code number was used instead of name.

\subsection{Methods of data collection}

(1) Approval was obtained from the Dean and Head of the Departments of the Faculty of Nursing, Tanta University.

(2) All tools of the study were developed by the researchers after reviewing relevant literature and used to collect data except Tool (III): Health Belief Model (HBM) was developed by Rosenstock ${ }^{[36]}$ and Janz and Becker. ${ }^{[37]}$

(3) The tools were tested for its content validity by a jury of 5 expertises in the area of Medical Surgical and Community Health Nursing, Their opinions were elicited regarding tools format, consistency and scoring system. Content of the tools were tested regarding to the knowledge accuracy, relevance and competence. It was calculated and found to be $97 \%$. Testing reliability for the study tools was calculated by alpha Cronbach's test: it was 0.91 for Tool (I), 0.96 for Tool (II) and 0.89 for Tool (III).

(4) A pilot study was conducted on (10\%) of the total study sample to test the feasibility and applicability of the tools and to determine any obstacles that may encountered during the period of data collection, accordingly, needed modification was done. Those students were excluded from the study sample.

(5) Data collection for this study was carried out at the beginning of October 2017 to the end of May 2018.

(6) Educational guidelines were conducted for undergraduate nursing students through four phases (assessment, planning, implementation and evaluation):

Assessment phase: Undergraduate male nursing students were assessed before starting educational guidelines by using Tool (I), Tool (II) and Tool (III) were used to evaluate nursing students knowledge, self-reported practice and health beliefs regarding testicular cancer and TSE to determine the needs of the undergraduate male nursing students and number of the sessions. All questionnaire sheets were filled by the students within 40 minutes.

Planning phase: The content of the educational guidelines about testicular cancer and TSE were prepared by the researchers based on the related literature. ${ }^{[41-45]}$ Objectives of the study were prepared based on the needs of the study students. An illustrative structured booklet was prepared and supported by pictures as a guide for the students, and different teaching methods were used as lectures, discussions, demonstration and redemonstration. A booklet was given to each undergraduate student during sessions to refresh their knowledge and practice. Educational guidelines were conducted for each group according to specific time of each department as following: 3 sessions within two weeks for each group, about two days per week where every group takes the same sessions in the same week according to their working days, the time of each session was about 2 hours.

Implementation phase: It was implemented by the researchers that included the schedule of educational guidelines which were divided into three educational sessions that are provided for each group according to specific time of each department in the same week as the following: The First session included pretest for all nursing students and providing knowledge about definitions, risk factors and manifestation of testicular cancer. The second session was included; knowledge about treatment and prevention of testicular cancer and health beliefs about testicular cancer and TSE. The 
third session was included knowledge and practice regarding demonstration of TSE.

Evaluation phase: 3-month post implementation of educational guidelines and 6-month later, the researchers were reevaluated knowledge and self-reported practice by using Tool (I) part (B) and Tool (I). Health belief of nursing students about testicular cancer and TSE were reevaluated 6month later post educational guidelines by using Tool (III).

\subsection{Methods of data analysis}

All data were collected, coded and tabulated to statistical analysis. Statistical analysis is performed by statistical Package SPSS in general (version 20), also Microsoft office Excel is used for data handling and graphical presentation variables. Data expressed as Mean and $S D, T$-test, number and percentage and chi-square are used to determine significant for numeric variable. Pearson's Correlation analysis was used to show strength and direction of association between two quantitative variables. A probability level of $p$-value $\leq .01$ was adopted as a level of significance for testing the research hypotheses.

\section{RESUlts}

Table 1 showed the distribution of the studied undergraduate male nursing students according to their socio-demographic data. As regard to age, the table showed that half of the students $(50 \%)$ were in the age group (> 20-22) years old with mean $20.07 \pm 1.12$. Regarding to academic year, the study subjects were as the following: first year (18.8\%), sec- ond year (20.6\%), third and fourth year (30\% and 30.6\%) respectively. Majority of students $(92.5 \%)$ had no family history of testicular cancer. Also, $71.3 \%$ of students never smoked.

Table 1. Distribution of the studied undergraduate male nursing students according to their socio-demographic characteristics

\begin{tabular}{lll}
\hline Socio-demographic & \multicolumn{2}{l}{ Student sample (N = 160) } \\
\cline { 2 - 3 } Characteristics & No & $\%$ \\
\hline Age (year) & & \\
$\quad<19$ & 40 & 25.0 \\
$19-20$ & 40 & 25.0 \\
$>20-22$ & 80 & 50.0 \\
Range & $18-22$ & \\
Mean \pm SD & $20.07 \pm 1.12$ \\
Academic Years & & \\
First & 30 & 18.8 \\
Second & 33 & 20.6 \\
Third & 48 & 30.0 \\
Fourth & 49 & 30.6 \\
Family history of testicular cancer & & \\
Yes & 12 & 7.5 \\
No & 148 & 92.5 \\
If yes mention member (12) & & \\
Father & 2 & 16.7 \\
Brother & 10 & 83.3 \\
Students smoking habit & & \\
Never smoked & 114 & 71.3 \\
actually smoking & 44 & 27.4 \\
previously smoking & 2 & 1.3 \\
\hline & & \\
\hline
\end{tabular}

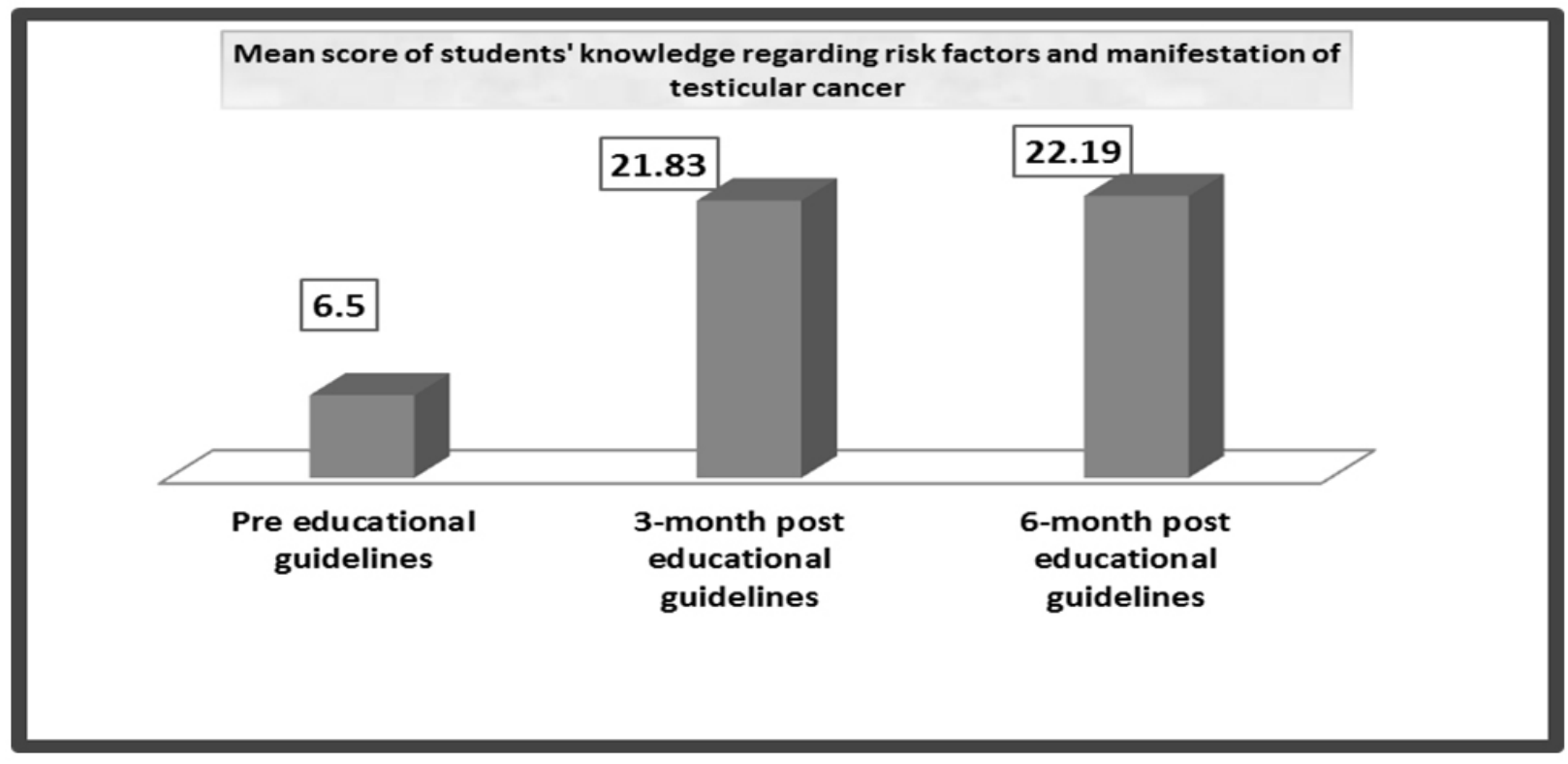

Figure 1. Mean score of students' knowledge regarding risk factors and manifestation of testicular cancer throughout all intervention periods of the study 
Figure 1 showed the mean score of students' knowledge regarding risk factors and manifestation of testicular cancer throughout all intervention periods of the study. The figure revealed that there were significant difference in the mean score of knowledge was observed from pre to 3month and 6-month later post educational guidelines with $p$-value $\leq .01$.
Figure 2 showed the mean score of students' knowledge regarding TSE throughout all intervention periods of the study. The figure revealed that there were significant difference in the mean score of knowledge was observed from pre to 3month and 6-month later post educational guidelines with $p$-value $\leq .01$.

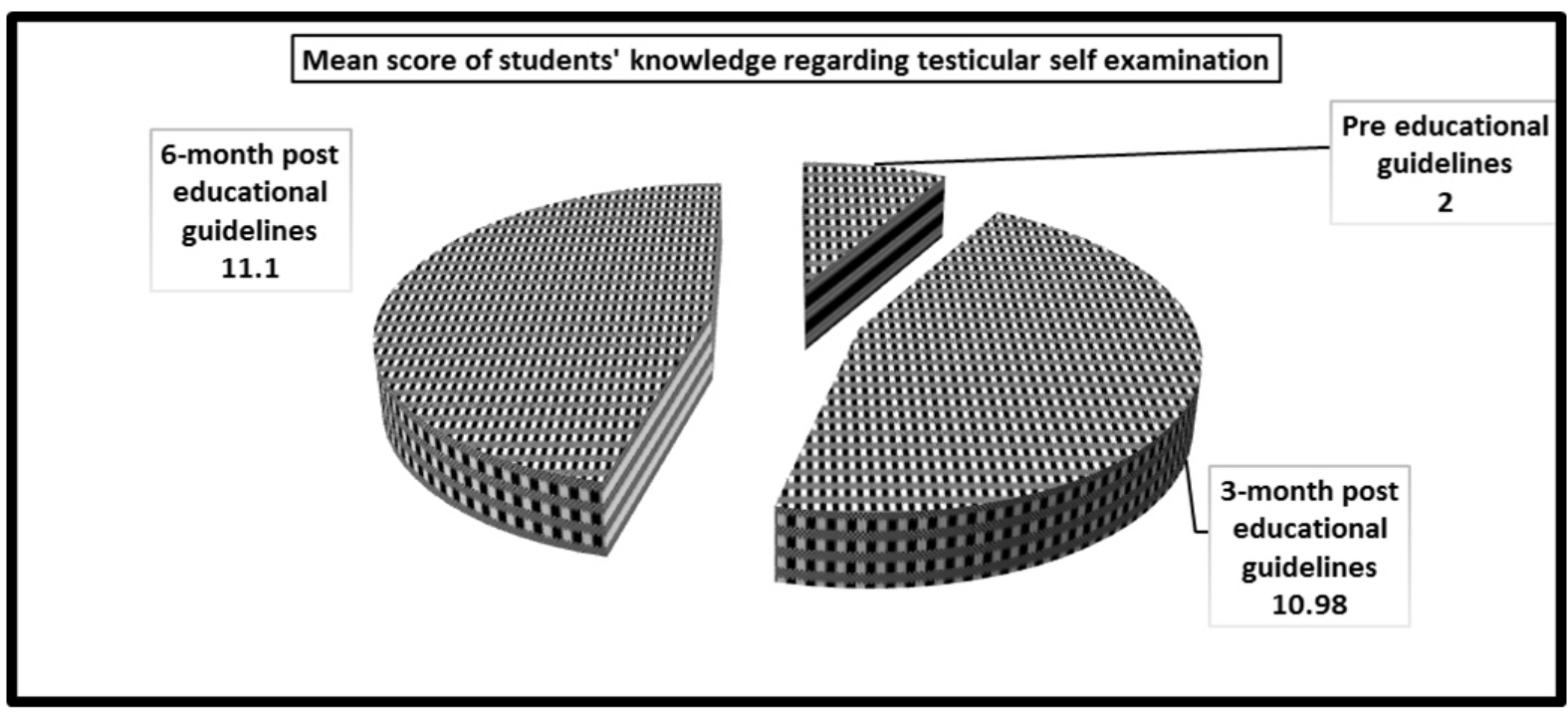

Figure 2. Mean score of students' knowledge regarding TSE throughout all intervention periods of the study

Figure 3 showed the score of students' knowledge regarding treatment and prevention of testicular cancer throughout all intervention periods of the study. The figure revealed that there were significant difference in the mean score of knowledge was observed from pre to 3-month and 6-month later post educational guidelines with $p$-value $\leq .01$.

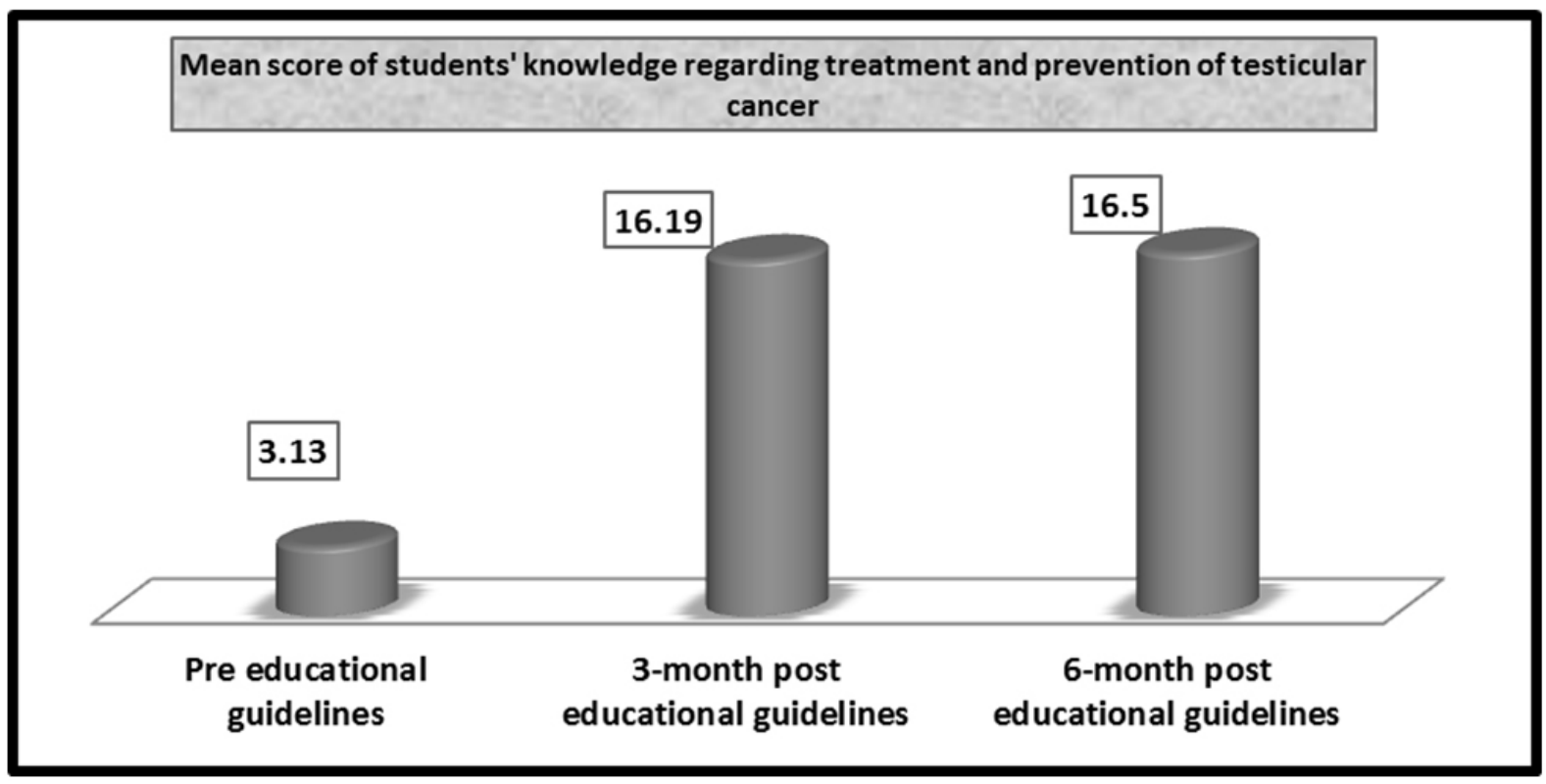

Figure 3. Mean score of students' knowledge regarding treatment and prevention of testicular cancer throughout all intervention periods of the study 
Figure 4 showed total mean score of students' knowledge score of knowledge was observed from pre to 3-month and throughout all intervention periods of the study. The figure 6 -month post educational guidelines with $p$-value $\leq .01$. revealed that there were significant difference in the total

Total mean score of students' knowledge throughout all intervention periods of the study

Pre educational guidelines

3-month post educational guidelines

6-month post educational guidelines

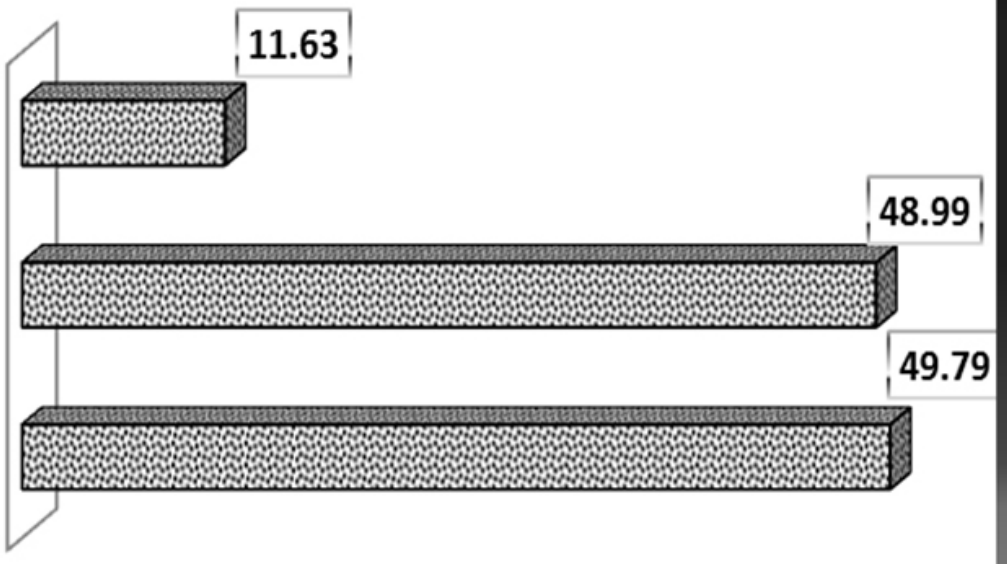

Figure 4. Total mean score of students' knowledge throughout all intervention periods of the study

Table 2. Percentage of studied students according to self-reported practices regarding TSE throughout all intervention periods of the study

\begin{tabular}{|c|c|c|c|c|c|c|c|c|}
\hline & \multicolumn{6}{|c|}{ The intervention group $(\mathbf{N}=160)$} & \multirow{3}{*}{$T$} & \multirow{3}{*}{$p$} \\
\hline & \multicolumn{2}{|c|}{$\begin{array}{c}\text { Pre intervention } \\
(\%)\end{array}$} & \multicolumn{2}{|c|}{$\begin{array}{c}\text { 3-month post } \\
\text { intervention }(\%)\end{array}$} & \multicolumn{2}{|c|}{$\begin{array}{c}\text { 6-month post } \\
\text { intervention }(\%)\end{array}$} & & \\
\hline & Done & Not done & Done & Not done & Done & Not done & & \\
\hline Prepare yourself before starting TSE & 20.0 & 80.0 & 78.1 & 21.9 & 91.3 & 8.8 & 19.85 & $.000^{* *}$ \\
\hline Perform TSE regularly every month & 20.0 & 80.0 & 85.6 & 14.4 & 85.6 & 14.4 & 25.22 & $.000^{* *}$ \\
\hline Conduct TSE in last three months & 20.6 & 79.4 & 78.1 & 21.9 & 92.5 & 7.5 & 19.56 & $.000^{* *}$ \\
\hline Perform TSE during a warm shower & 20.6 & 79.4 & 70.6 & 29.4 & 84.4 & 15.6 & 15.51 & $.000^{* * *}$ \\
\hline Wet and soapy scrotum during examination & 31.3 & 68.8 & 87.5 & 12.5 & 92.5 & 7.5 & 15.08 & $.000^{* * *}$ \\
\hline Make TSE when stand in front of a mirror & 11.3 & 88.8 & 82.5 & 17.5 & 91.3 & 8.8 & 23.45 & $.000^{* * *}$ \\
\hline Cup scrotum with one hand during examination & 20.6 & 79.4 & 77.5 & 22.5 & 90.6 & 9.4 & 18.21 & $.000^{* *}$ \\
\hline Assess tenderness if present during examination & 11.3 & 88.8 & 82.5 & 17.5 & 91.3 & 8.8 & 23.45 & $.000^{* *}$ \\
\hline Check for any swelling on the scrotal skin & 26.9 & 73.1 & 78.8 & 21.3 & 93.8 & 6.3 & 16.98 & $.000^{* *}$ \\
\hline Examine each testicle gently with both hands & 36.9 & 63.1 & 87.5 & 12.5 & 92.5 & 7.5 & 13.45 & $.000^{* *}$ \\
\hline Feel the size and weight of the testicles & 11.9 & 88.1 & 70.6 & 29.4 & 88.1 & 11.9 & 20.00 & $.000^{* *}$ \\
\hline Roll testicles gently between thumbs and fingers & 16.3 & 83.8 & 73.1 & 26.9 & 94.4 & 5.6 & 22.25 & $.000^{* * *}$ \\
\hline Feel along the epididymis for swelling & 11.9 & 88.1 & 70.6 & 29.4 & 84.4 & 15.6 & 20.00 & $.000^{* * *}$ \\
\hline
\end{tabular}

Note. ${ }^{* *}$ Highly significant $p$-value $\leq .01$ 
Table 2 showed the percentage of students according to selfreported practice regarding TSE throughout all intervention periods of the study. The table revealed that there were significant improvement in students practice regarding; prepare themselves before starting TSE, perform TSE every month, conduct TSE in last three months, perform TSE during a warm shower, make TSE when stand in front of a mirror, cup scrotum with hand, check swelling on the scrotal skin, examine testicle gently with both hands, feel size and weight of the testicles, roll the testicles gently between thumbs and fingers from pre to 3-month and 6-month later post educational guidelines intervention with statistically significant difference with $p$-value $\leq .01$.

Figure 5 showed the total mean score of self-reported practices regarding TSE throughout all intervention periods of the study. The figure revealed that there was significant difference in the total mean score of self-reported practice which was observed from pre to 3-month and 6-month post educational guidelines with $p$-value $\leq .01$.

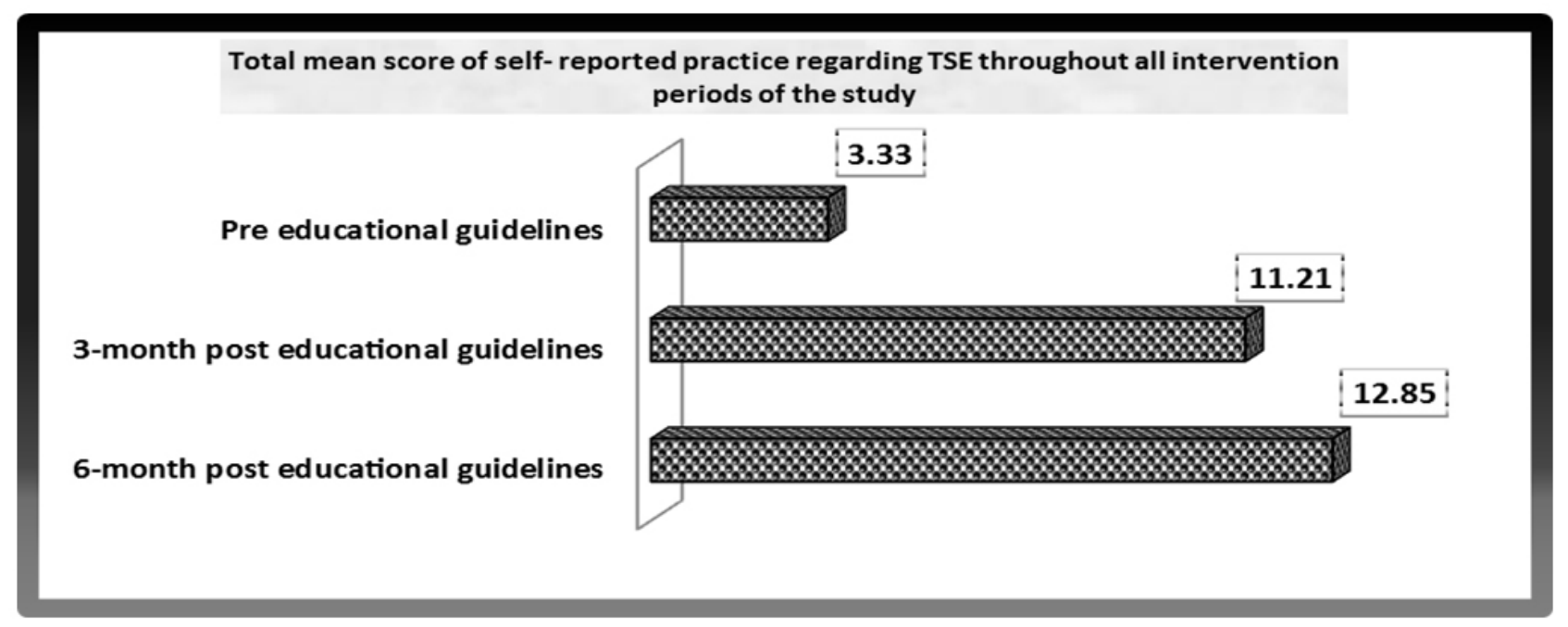

Figure 5. Total mean score of self-reported practice regarding TSE throughout all intervention periods of the study

Table 3 showed the percentage of the students regarding health belief about testicular cancer pre and 6-month post educational guidelines. Regarding to susceptibility the students perceived highly susceptibility to the disease where; they feel possibility about having TC in a few years, fear from dying of TC and in comparison to a male peer, possibility that have TC; from agree pre guidelines $(85.0 \%, 75.0 \%$ and $80.6 \%)$ respectively to disagree $(85.6 \%, 91.3 \%$ and $89.4 \%)$ respectively post 6-month from guidelines. Regarding to Seriousness, students perceived high level of seriousness of disease that means they feel TC scares him, heartbeat gets faster when think of TC, suffer from various problems for a long period of time if I have TC, having TC will threaten relationship with family, if I have TC whole life will change, TC is a hopeless disease, having TC would put financial security in danger, TC would put future professional life in danger., TC would end sexual life as following; from agree pre guidelines $(83.8 \%, 78.1 \%, 71.3 \%, 71.3 \%, 71.9 \%, 76.3 \%, 79.4 \%$, $79.4 \%$ and $78.8 \%)$ respectively to disagree $(86.9 \%, 90.0 \%$,
$89.4 \%, 88.1 \%, 93.1 \%, 86.9 \%, 86.9 \%, 91.3 \%$ and $80.6 \%)$ respectively post 6-month from guidelines. Regarding to Benefits and health motivation, students perceived high level of benefits about all items were observed from disagree pre to agree post 6-month from guidelines.

Table 4 showed the percentage of the studied students regarding health belief items: Barriers and self-efficacy about TC pre and 6-month post educational guidelines. The table showed that the students disagreed with perceived barriers regarding all items from pre guidelines to post 6-month. For about self-efficacy, students perceived high level self-efficacy regarding know how to do self-examination, can do TSE correctly, can find a lump in testicles by doing self-examination, and can say that have a problem in testicles by doing selfexamination, from disagree pre guidelines $(75.6 \%, 76.3 \%$, $78.8 \%$ and $74.4 \%)$ respectively to agree $(92.5 \%, 91.3 \%$, $90.0 \%$ and $90.6 \%$ ) respectively post 6 -month from guidelines. 
Table 3. Percentage of the studied students regarding health belief items: Susceptibility, Seriousness, Benefits and health motivation about testicular cancer at pre and 6-month post educational guidelines

\begin{tabular}{|c|c|c|c|c|c|c|}
\hline \multirow{3}{*}{ Items } & \multicolumn{6}{|c|}{ The intervention group $(\mathrm{N}=160)$} \\
\hline & \multicolumn{3}{|c|}{ Pre-intervention (\%) } & \multicolumn{3}{|c|}{ 6-month post-intervention (\%) } \\
\hline & Agree & Neutral & Disagree & Agree & Neutral & Disagree \\
\hline \multicolumn{7}{|l|}{ Perceived Susceptibility } \\
\hline 1. The possibility that I have TC is very high. & 80.6 & 5.6 & 13.8 & 4.4 & 10.6 & 85.0 \\
\hline 2. Possibility that I have TC in a few years is high. & 85.6 & 0 & 14.4 & 8.8 & 6.3 & 85.0 \\
\hline 3. I feel that I will have TC in some part of my life. & 83.8 & 5.6 & 10.6 & 7.5 & 7.5 & 85.0 \\
\hline 4. I fear from dying of testicular cancer. & 91.3 & 6.3 & 2.5 & 13.1 & 11.9 & 75.0 \\
\hline 5.In comparison to a male peer, possibility that I have T.C. & 89.4 & 5.6 & 5.0 & 12.5 & 6.9 & 80.6 \\
\hline \multicolumn{7}{|l|}{ Perceived Seriousness } \\
\hline 6. The thought of testicular cancer scares me. & 86.9 & 0 & 13.1 & 16.3 & 0 & 83.8 \\
\hline 7. My heartbeat gets faster when I think of T.C. & 90.0 & 1.3 & 8.8 & 15.0 & 6.9 & 78.1 \\
\hline 8. I will suffer from problems for a long time if I have T.C. & 89.4 & 8.1 & 2.5 & 14.4 & 14.4 & 71.3 \\
\hline 9. Having TC will threaten relationship with family & 88.1 & 2.5 & 9.4 & 18.8 & 10.0 & 71.3 \\
\hline 10. If I have TC, my whole life will change. & 93.1 & 1.3 & 5.6 & 24.4 & 3.8 & 71.9 \\
\hline 11. Testicular cancer is a hopeless disease. & 86.9 & 2.5 & 10.6 & 16.9 & 6.9 & 76.3 \\
\hline 12. Having T.C. put my financial security in danger. & 86.9 & 5.6 & 7.5 & 15.6 & 5.0 & 79.4 \\
\hline 13. TC put future professional life in danger. & 91.3 & 1.3 & 7.5 & 17.5 & 3.1 & 79.4 \\
\hline 14. Testicular cancer would end my sexual life. & 80.6 & 10.6 & 8.8 & 6.9 & 14.4 & 78.8 \\
\hline 15. If I have testicular cancer, I will be infertile. & 75.0 & 17.5 & 7.5 & 0 & 22.5 & 77.5 \\
\hline \multicolumn{7}{|l|}{ Perceived Benefits and health motivation } \\
\hline 16. I search for information to improve my health. & 15.0 & 12.5 & 72.5 & 83.1 & 10.6 & 6.3 \\
\hline 17. Finding problems at early stage is important. & 18.8 & 6.3 & 75.0 & 88.1 & 1.3 & 10.6 \\
\hline 18. Staying healthy is very important to me. & 16.9 & 11.9 & 71.3 & 83.8 & 9.4 & 6.9 \\
\hline 19. I think it is important to do things benefit health. & 18.8 & 6.9 & 74.4 & 88.1 & 3.8 & 8.1 \\
\hline 20. If I do TSE, I will be less likely to die of T.C. & 19.4 & 3.1 & 77.5 & 88.1 & 0 & 11.9 \\
\hline 21. I have a successful treatment if I find a lump by TSE. & 11.9 & 10.6 & 77.5 & 81.9 & 6.3 & 11.9 \\
\hline 22. I eat a balanced diet. & 22.5 & 7.5 & 70.0 & 91.9 & 5.6 & 2.5 \\
\hline 23. I exercise at least three times a week. & 18.1 & 7.5 & 74.4 & 90.6 & 5.6 & 3.8 \\
\hline 24. I have checkups regularly even if I am not ill. & 15.0 & 13.1 & 71.9 & 90.0 & 7.5 & 2.5 \\
\hline
\end{tabular}

Table 4. Percentage of the studied students regarding health belief items; Barriers and self-efficacy about testicular cancer at pre and 6-month post educational guideline

\begin{tabular}{|c|c|c|c|c|c|c|}
\hline \multirow{3}{*}{ Items } & \multicolumn{6}{|c|}{ The intervention group $(\mathrm{N}=160)$} \\
\hline & \multicolumn{3}{|c|}{ Pre-intervention $(\%)$} & \multicolumn{3}{|c|}{ 6-monthes post-intervention (\%) } \\
\hline & Agree & Neutral & Disagree & Agree & Neutral & Disagree \\
\hline \multicolumn{7}{|l|}{ Perceived Barriers } \\
\hline 25. I find it boring to do TSE every month. & 1.2 & 30.0 & 68.8 & 0 & 13.1 & 86.9 \\
\hline 26. It takes a long time to do TSE. & 5.0 & 25.6 & 69.4 & 5.6 & 7.5 & 86.9 \\
\hline 27. Testicular self-examination is painful. & 6.3 & 27.5 & 66.3 & 5.0 & 11.9 & 83.1 \\
\hline 28. If I do TSE, my family will make fun of me. & 5.0 & 30.6 & 64.4 & 5.0 & 11.9 & 83.1 \\
\hline 29. It is difficult to remember to do TSE. & 7.5 & 23.8 & 68.8 & 6.3 & 6.9 & 86.9 \\
\hline 30. I do not have the privacy required to do TSE. & 5.0 & 21.9 & 73.1 & 5.0 & 6.9 & 88.1 \\
\hline 31. I will not need to do self-examination. & 5.0 & 22.5 & 72.5 & 5.0 & 8.1 & 86.9 \\
\hline 32. I do not do TSE since I am afraid of finding a lump. & 8.8 & 21.3 & 70.0 & 11.3 & 2.5 & 86.3 \\
\hline 33. I have important problems than doing TSE. & 12.5 & 15.0 & 72.5 & 11.3 & 2.5 & 86.3 \\
\hline \multicolumn{7}{|l|}{ Perceived Self-efficacy } \\
\hline 34. I know how to do self-examination. & 20.6 & 3.8 & 75.6 & 92.5 & 0 & 7.5 \\
\hline 35. I can do TSE correctly. & 18.1 & 5.6 & 76.3 & 91.3 & 1.3 & 7.5 \\
\hline 36. I can find a lump in my testicles by doing TSE. & 15.0 & 6.3 & 78.8 & 90.0 & 1.3 & 8.8 \\
\hline 37. I can have a problem in my testicles by doing TSE. & 18.1 & 7.5 & 74.4 & 90.6 & 5.6 & 3.8 \\
\hline
\end{tabular}


Figure 6 showed the total mean score of health belief of undergraduate nursing students at pre guidelines and 6-month post educational guidelines. The figure revealed that there was significant difference in the total mean score of health belief regarding; susceptibility, seriousness, benefits, health motivation, barriers and self-efficacy which was observed from pre guidelines to 6-month post educational guidelines at $p$-value $\leq .01$.

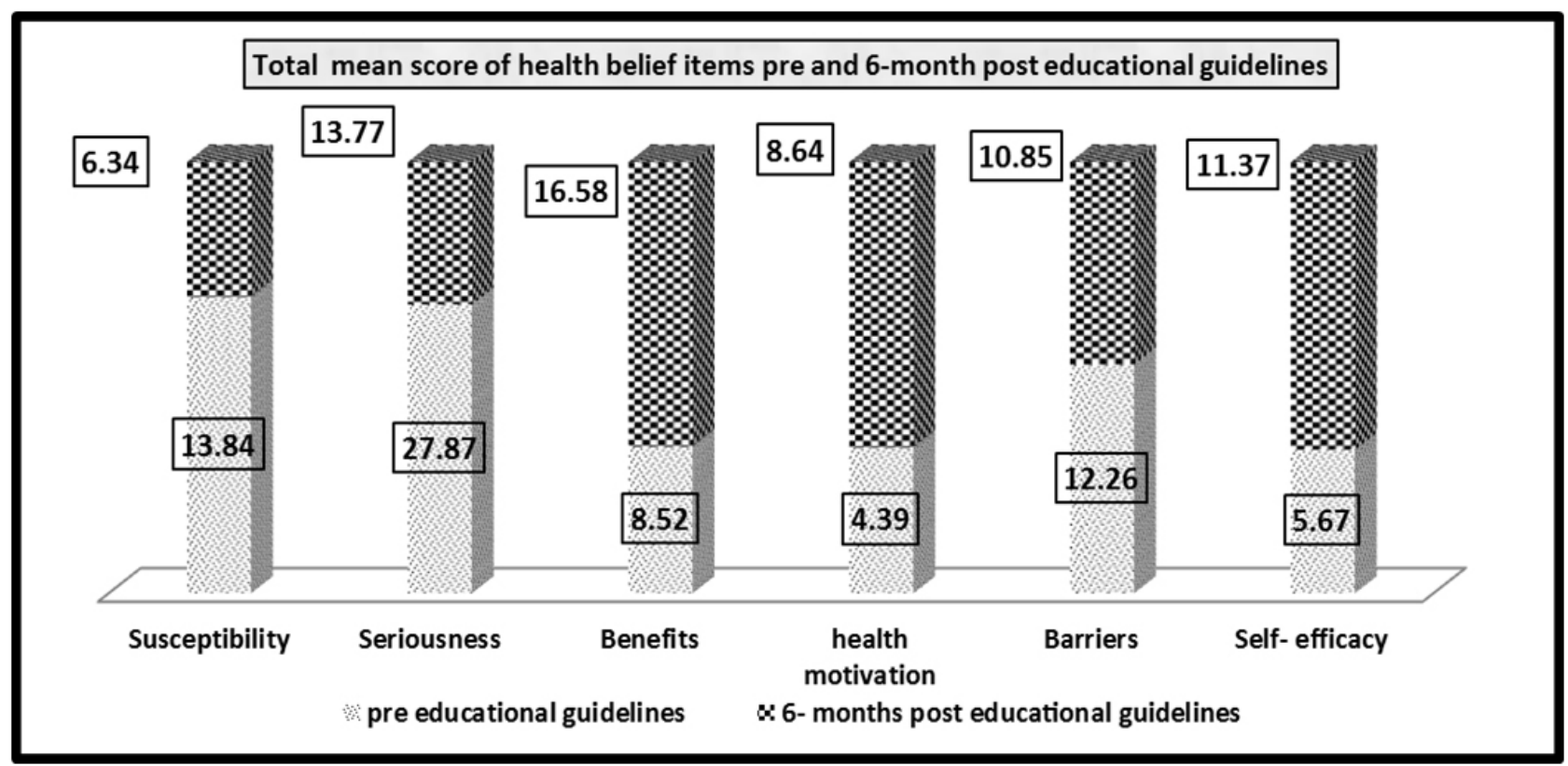

Figure 6. Total mean score of health Belief items pre and 6-month post educational guidelines

Table 5 showed the correlation among socio-demographic data for students and knowledge \& practice regarding testicular cancer and TSE throughout all intervention periods of the study. As regard to knowledge, the table showed that there were statistical significant positive correlations among students' knowledge and age, academic year, and smoking habits from pre to 3-month and 6-month post educational guidelines with $p$-value .01 . Also the table showed that there were statistical significant positive correlations among students' practice and age, academic year, and smoking habits from pre to 3-month and 6-month later post educational guidelines with $p$-value .01 .

Table 5. Correlation among socio-demographic data for students and knowledge \& practice regarding Testicular cancer and TSE throughout all intervention periods of the study

\begin{tabular}{|c|c|c|c|c|c|c|}
\hline $\begin{array}{l}\text { Items of } \\
\text { correlation }\end{array}$ & & $\begin{array}{l}\text { Pre guidelines } \\
\text { total knowledge } \\
\text { score }\end{array}$ & $\begin{array}{l}\text { 3-month post } \\
\text { guidelines total } \\
\text { knowledge score }\end{array}$ & $\begin{array}{l}\text { 6-month post } \\
\text { guidelines total } \\
\text { knowledge score }\end{array}$ & $\begin{array}{l}\text { 3-month post } \\
\text { guidelines total } \\
\text { practical score }\end{array}$ & $\begin{array}{l}\text { 6-month post } \\
\text { guidelines total } \\
\text { practical score }\end{array}$ \\
\hline \multirow[b]{2}{*}{ Age } & $r$ & 0.597 & 0.890 & 0.696 & 0.871 & 0.669 \\
\hline & $p$ & $.000^{* *}$ & $.000^{* *}$ & $.000^{* *}$ & $.000^{* *}$ & $.000^{* *}$ \\
\hline \multirow{2}{*}{ Academic year } & $r$ & 0.808 & 0.856 & 0.807 & 0.834 & 0.784 \\
\hline & $p$ & $.000^{* *}$ & $.000^{* *}$ & $.000^{* *}$ & $.000^{* *}$ & $.000^{* *}$ \\
\hline \multirow{2}{*}{$\begin{array}{l}\text { Family history of } \\
\text { testicular cancer }\end{array}$} & $r$ & 0.252 & 0.249 & 0.128 & 0.240 & 0.119 \\
\hline & $p$ & $.001^{* *}$ & $.002^{* *}$ & .107 & $.002^{* *}$ & 0.134 \\
\hline \multirow{2}{*}{ Smoking habit } & $r$ & 0.797 & 0.490 & 0.464 & 0.472 & 0.471 \\
\hline & $p$ & $.000^{* *}$ & $.000^{* *}$ & $.000^{* *}$ & $.000^{* *}$ & $.000^{* *}$ \\
\hline
\end{tabular}

Note. ${ }^{* *}$ Correlation is significant at the 0.01 level (2-tailed) 
Table 6. Correlation among total knowledge and total practice for male students regarding testicular cancer and TSE throughout all intervention periods of the study

\begin{tabular}{llll}
\hline Items of correlation & & $\begin{array}{l}\text { 3-month post guidelines total } \\
\text { practical score }\end{array}$ & $\begin{array}{l}\text { 6-month post guidelines total } \\
\text { practical score }\end{array}$ \\
\hline Pre guidelines score of knowledge & $r$ & 0.556 & 0.673 \\
& $p$ & $.000^{* *}$ & $.000^{* *}$ \\
3-month post guidelines total score of & $r$ & 0.949 & 0.646 \\
knowledge & $p$ & $.000^{* *}$ & $.000^{* *}$ \\
6-month post guidelines total score of & $r$ & 0.647 & 0.943 \\
knowledge & $p$ & $.000^{* *}$ & $.000^{* *}$ \\
\hline
\end{tabular}

Note. ${ }^{* *}$ Correlation is significant at the 0.01 level (2-tailed)

Table 7. Correlation among socio-demographic data for students and health belief regarding Testicular cancer and TSE at pre and 6-month post educational guidelines

\begin{tabular}{llll}
\hline Items of correlation & & Total health belief pre guidelines & Total health belief 6-month post guidelines \\
\hline \multirow{2}{*}{ Age } & $r$ & 0.102 & 0.660 \\
& $p$ & .201 & $.000^{* *}$ \\
Academic year & $r$ & 0.056 & 0.587 \\
& $p$ & 0479 & $.000^{* *}$ \\
Family history of testicular cancer & $r$ & 0.119 & 0.125 \\
& $p$ & .135 & .116 \\
Smoking habit & $r$ & 0.160 & 0.264 \\
& $p$ & $.034^{* *}$ & $.002^{* *}$ \\
\hline
\end{tabular}

Note. ${ }^{*}$ Correlation is significant at the .05 level (2-tailed); ${ }^{* *}$ Correlation is significant at the .01 level (2-tailed)

Table 6 showed the correlation among total knowledge and total practice for students regarding testicular cancer and TSE throughout all intervention periods of the study. The table showed that there were statistical significant positive correlations among students' knowledge and practice from 3month and 6-month post educational guidelines with $p$-value .01 .

Table 7 showed the correlation among socio-demographic data for students and health belief regarding Testicular cancer and TSE at pre guidelines and 6-month post educational guidelines. The table showed that there were statistical significant positive correlations among students' health belief and age, academic year, and smoking habits from pre guidelines and 6-month post educational guidelines with $p$-value .01 .

\section{Discussion}

Globally, testicular cancer accounts for approximately one percent of all cancers in men and has doubled in the last 40 years. Early detection of the disease through implementation of health educational guidelines leads to increase cure rate

Published by Sciedu Press for about $96 \%$, it can be facilitated if men are knowledgeable and encouraged to perform of TSE. ${ }^{[27]}$ This study aimed to evaluate the effect of educational guidelines based on health belief model regarding testicular cancer knowledge, practice and beliefs among male nursing students.

Concerning to socio-demographic characteristics of the male students, the study result revealed that half of the students were in the age from $>20-22$ years old, the study subjects were taken from all years of the faculty. Majority of students had no family history of testicular cancer and nearly three quarter of them never smoked. This result was in the same line with Ramim et al., ${ }^{[46]}$ who reported that in study about testicular cancer among students in medical sciences University that the age of the students were ranged from 17 to 41 years old and approximately two thirds of them were in first and second years. In the same line Pour et al., ${ }^{[47]}$ mentioned that in study about TSE the mean age of the students were $20.60 \pm 1.89$, whereas inconsistent regarding smoking result that he reported about $49.1 \%$ of the students were smoking.

Regarding to male nursing students' knowledge about testicular cancer and TSE, the study results revealed that there 
were highly statistically significant improvements in students mean score of knowledge regarding; risk factors, manifestation, treatment $\&$ prevention and TSE from pre to 3-month and 6-month later post educational guidelines with $p$-value $\leq .01$. This findings of low knowledge may be attributed to the nature of university environment where there were decrease interesting regarding health education about this type of cancer and it could be inferred that respondents directly obtained information from academic and social environment and increasing level of students knowledge post guidelines due to increase exploration through guidelines about risks and importance of regular of TSE.

These results were in the same line with Onyiriuka and Imoebe ${ }^{[48]}$ who reported that the majority of the students demonstrated very low level of knowledge about testicular cancer risks, manifestation and prevention and TSE technique pre educational guidelines that are improved post ending of guidelines. In addition to Ramim et al., ${ }^{[46]}$ mentioned that the knowledge of testicular cancer and TSE was poor, only $2.2 \%$ had good level of knowledge about testicular cancer risks, causes and its symptoms and less than $17 \%$ of participants had good score about TSE procedure which increased need for educational program.

Also Agorye et al. ${ }^{[31]}$ revealed that knowledge about TSE and testicular cancer was poor, only $9.2 \%$ of the students were aware that testicular lump that could be a sign of testicular cancer and these knowledge improved after educational program. Moreover, Ugboma and Aburoma ${ }^{[49]}$ and Kuzgunbay et al. ${ }^{[50]}$ reported that in the findings of their study that young men have a relatively low level of TC knowledge. Despite more than $78 \%$ of male answered that they knew TC, only $51.9 \%$ of male choose the lump or increase in testis size as the most common symptom and only $15 \%$ of male knew the most common age at diagnosis. In addition to Pour et al. ${ }^{[47]}$ who mentioned that before educational program about tescticular cancer about more than half of the students did not know any information about TSE and this affected on performance of TSE.

Regarding to students' self-reported practice about TSE, the study results revealed that there were significant improvement in the students practice regarding; ability to prepare themself before starting TSE, perform TSE regularly every month, conduct TSE in last three months, perform TSE during a warm shower, make skin of scrotum is soapy during exam, make TSE when stand in front of a mirror, assess pain or tenderness, check swelling on the scrotal skin, examine each testicle with both hands, feel size and weight of the testicles, feel along the epididymis for swelling. Also there were highly statistically significant improvement in the total mean score of self-reported practice regarding TSE from pre 3-month and 6-month later post educational guidelines.

This findings of low level of self-reported practice may be attributed to that the study sample beliefs TSE practice is important in general, but may be not for them at their young age, also the best explanation for the low level of TSE is probably due to lack of knowledge about testicular cancer and TSE. These results were in the same line with study that are carried out by McCullagh et al. ${ }^{[16]}$ in the United Kingdom, who reported that the performance of TSE increased from 58.4\% to $69.3 \%$ among the study participants after implementation of training program. Moreover, Mohamadloo and Mohamad${ }^{10}{ }^{[51]}$ reported that in their study, the self-reported practice of TSE during the previous year indicated that almost more than half of the participants ${ }^{[32]}$ never self-examined, ${ }^{[8]}$ selfexamined once a month, ${ }^{[5]}$ self-examined twice a month and self-examined three a month. ${ }^{[1]}$

In addition to Akar and Bebiş ${ }^{[52]}$ who reported that the majority of study participants were unaware of TSE and did not do it before the health educational intervention. In the same line Etita et al. ${ }^{[27]}$ revealed that low practices of TSE among male undergraduate students of the University of Calabar even those that practiced did so irregularly and not as recommended. In addition to Wynd ${ }^{[11]}$ who reported in his study that about $32 \%$ had knowledge about TSE, 22\% practiced TSE, from male undergraduate and postgraduate students in a British university, but only one respondent reported regular TSE performance.

Regarding to students' health belief about testicular cancer and TSE. The study results revealed that there were positive perceived in the different subscales of health belief from pre to 6-month post educational guidelines. Susceptibility to the disease is one of the strongest perceptions shown to influence individual to adopt healthy behaviors. This study revealed that majority of the students' perceived highly susceptibility to the cancer. As regard to seriousness majority of the students' perceived high level of seriousness of disease that means they feel threat from testicular cancer as a disease, thought of TC scares him, suffer from problems for a long period of time if I have TC. Also majority of the students' had high level of benefits and motivation and majority of them disagreed with perceived barriers pre and post intervention and is considered the strongest aspect of health believes.

Also the study results revealed that there were significant change in the students behavior regarding total mean score of health belief items; susceptibility, seriousness, benefits, health motivation, barriers and self-efficacy that were observed from pre to 6-month post educational guidelines. These results may attributed to the believes of the students 
that this type of cancer affect only older age groups according to physiological changes which lead to decrease motivation to inform themselves about prevention methods of testicular cancer as TSE, but post educational guidelines positive improvement in the students behavior was observed which revealed that the importance of increase students' knowledge and motivation regarding this type of cancer.

These results were in the same line with Pour et al., ${ }^{[46]}$ who showed a significant increase in the perceived benefits in terms of TSE. Furthermore a positive improvement in the behavior of the students toward TSE was observed after educational guidelines. These results indicate that TSE training is effective for better self-efficacy. Also Avic et al. ${ }^{[53]}$ reported that TSE is a health protective behavior. If students do it regularly self-efficacy and benefits levels of students were higher than those who did not. Moreover Muliira et al. $^{[54]}$ and Peltzer and Pengpid ${ }^{[55]}$ reported that students did not perceive TSE to be important, even if it was, not for their young age, the youths' seems belief that they are not at risk of developing any ill health and that serious ailments like TC were more associated with advancement in age but this belief changed post educational program.

In addition to Taymoori and Berry ${ }^{[56]}$ who revealed that early detection of testicular cancer and TSE showed that education is an important prerequisite for change positive intention and behavior of students. Moreover Akar and Bebiş ${ }^{[52]}$ mentioned that after the intervention program about TSE the perceived susceptibility to TC and the perceived severity of $\mathrm{TC}$ are high. In addition the perceived barriers will increased and significant difference in health beliefs will be detected. Also Brown et al. ${ }^{[57]}$ reported that audiovisual material used in the interactive group increased the perceived benefits and minimized the obstacles associated with TSE and greater perceived self-efficacy was associated with the interactive educational strategy.

The study results revealed that there were statistical significant positive correlations among students' knowledge \& practice and socio-demographic data for students as: age, academic year, and smoking habits from pre to 3-month and 6-month post educational guidelines. This result was not in the same line with Ramim et al., ${ }^{[46]}$ who reported that in his study, students' age was not correlated to testicular cancer knowledge but Kruskal Wallis test did not show any difference among student years at the university with regard to testicular cancer awareness and performance of TSE, while a significant correlation between TSE knowledge and entry year's to university was observed.

Regarding to correlations among students' knowledge and practice. The study results revealed that there were statistical significant positive correlations among students' knowledge and practice pre to 3-month and 6-month post educational guidelines. This was in the same line with Ingwu et al., ${ }^{[58]}$ who reported that A chi-square value of 69.4 was obtained at $p<.05$, showing a significant correlation between knowledge of testicular cancer and practice of TSE. It therefore implies that good knowledge will increase practice of TSE and vice versa. This could probably be attributed to the fact that the students did not have the confidence and competency to carry of TSE.

Regarding to correlations among students' health belief and socio-demographic data for students, the study results revealed that there were statistical significant positive correlations among students' health belief and socio-demographic data for students as; age, academic year, and smoking habits from pre to 6-month post educational guidelines. This was in the same line with Hables ${ }^{[59]}$ who revealed that there were a statistically significant relation was observed between the present study participants' health beliefs and their age. Also statistically significant correlation was observed between health beliefs about self-examination and family history was detected.

\section{Conclusions}

In the light of the current study, it can be concluded that: There were statistical significant improvements of students' knowledge and practice regarding testicular cancer and TSE 3-month and 6-month later post educational guidelines than pre intervention period. Furthermore, a significant improvement in the behavior of the students toward TSE was observed post 6-month from application of educational guideline. Also there were statistical significant positive correlations among knowledge and practice and socio-demographic characteristic of students as well as health belief.

\subsection{Recommendation}

Based on the results of the present study recommendation are suggested that:

(1) It is necessary to raise the knowledge of the students in terms of TC and TSE, health education given by the health care providers should be planned and started at the schools.

(2) There is an urgent need for interventions to promote men's awareness of testicular disorders and increase their intentions to seek help for testicular symptoms.

(3) Further research on large scale is required to investigate barriers influencing of TSE practice among Egyptian males and how to perform TSE method through all parts of society and age categories.

(4) Study should be repeated for the first and second year 
students again when they are fourth year students as a longitudinal study.

\subsection{Limitation of the study}

The limitations of this study were:

(1) Lack of interesting of some male nursing students regarding this type of cancer before educational guidelines, where they believes that, it affect only old age groups of male.
(2) Also male nursing students may have been affected by the sensitive questions.

\section{ACKNOWLEDGEMENTS}

The researchers thank the male nursing students.

\section{CONFlicts OF InTEREST Disclosure}

The authors declare they have no conflicts of interest.

\section{REFERENCES}

[1] Cotton R. Like it or lump it: getting boys to self-examine. British Journal of School Nursing. 2009; 4(5): 245-8. https : //doi .org/ $10.12968 /$ bjsn.2009.4.5.42780

[2] Fessenden C. Adoption of testicular self-examination [Ph.D.]. United States - Michigan: Wayne State University; 2002. 30 p.

[3] Khadra A, Oakeshott P. Pilot study of testicular cancer awareness and testicular self-examination in men attending two South London general practices. Family Practice. 2002; 19(3): 294-6. PMid: 11978722. https://doi.org/10.1093/fampra/19.3.294

[4] Rew L, McDougall G, Riesch L, et al. Development of the selfefficacy for testicular self-examination scale. The Journal of Men's Health \& Gender. 2005; 2(1): 59-63. https ://doi .org/10.101 $6 / j \cdot j m h g \cdot 2004.12 .007$

[5] Moore R, Topping A. Young men's knowledge of testicular cancer and testicular self-examination: a lost opportunity? European Journal of Cancer Care. 1999; 8(3): 137-42. https://doi .org/10.1046/ j.1365-2354.1999.00151.x

[6] Tanagho E, McAninch J. Smith's General Urology. 16th ed. Tehran: Timourzadeh, Mosby Com; 2005. 222 p.

[7] Holdstock R. Testicular cancer. Practice Nurse. 2010; 40(1): 26-9.

[8] Vasudev N, Joffe J, Cooke C, et al. Delay in the diagnosis of testicular tumors - changes over the past 18 years. The British Journal of General Practice: the Journal of the Royal College of General Practitioners. 2004; 54(505): 595-7.

[9] Clèries R, Martínez J, Escribà J, et al. Monitoring the decreasing trend of testicular cancer mortality in Spain during 2005-2019 through a Bayesian approach. Cancer Epidemiology. 2010; 34(3): 244-56. PMid: 20381445. https://doi.org/10.1016/j.canep. 2010 .03 .003

[10] Ward K, Vander M, Read M, et al. Testicular cancer awareness and self-examination among adolescent males in a communitybased youth organization. Preventive Medicine. 2005; 41(2): 38698 PMid: 15917035. https://doi.org/10.1016/j.ypmed. 2005 .02 .003

[11] Wynd C. Testicular Self Examination in Young Adult Men. Journal of Nursing Scholarship. 2012; 34(3): 251-5. https ://doi .org/10 $.1111 / j .1547-5069.2002 .00251 . x$

[12] The American Cancer Society's. Available from: https : //www. cancer.org/research/cancer-facts.C ancer./cancer-facts-figures-2017

[13] Cancer.Net Editorial Board. 2016. Available from: https://www . cancer.net/about-us/cancernet-editorial-board

[14] National Cancer Institute. Testicular Cancer. 2010. Available from: http://seer.cancer.gov/statfacts/html/testis. htmlincidence-mortality
[15] Casey G, Grainger R, Butler R, et al. Public awareness of testis cancer and the prevalence of testicular self-examination-changing patterns over 20 years. Urology Journal. 2010; 76: 915-8. PMid: 20471670. https://doi.org/10.1016/j.urology.2010.03.022

[16] McCullagh J, Lewis G, Warlow C. Promoting awareness and practice of testicular self-examination. Nurs Stand. 2005; 19: 41-9. https://doi.org/10.7748/ns.19.51.41.s55

[17] Robert J, George J. Testicular Cancer. Harrison's Principles of Internal Medicine. 16th ed. Mc Graw-Hill. 2005; 550-553.

[18] Smeltzer C, Bare G, Hinkle L, et al. Brunner and Suddarth's textbook of medical-surgical nursing. 12th ed. Chapter 49 Philadelphia: Lippincott Williams \& Wilkins. 2010; 200: 201.

[19] Feldman R, Bosl J, Sheinfeld J, et al. Medical treatment of advanced testicular cancer. JAMA. 2008; 299(6): 672-684. PMid: 18270356 https://doi.org/10.1001/jama.299.6.672

[20] World Health Organization. World Cancer Report 2014. WHO; 2014. Report No.: 3. Available from: www.iarc.fr/en/publications/ books/wcr/wcr-order.php

[21] Gutema H, Debela Y, Walle B, et al. Testicular self-examination among Bahir Dar University students: application of integrated behavioral model. BMC Cancer. 2018; 18: 21. PMid: 29301513. https ://doi.org/10.1186/s12885-017-3935-8

[22] Nguyen M, Ellison M. Testicular cancer patterns in Asian-American males: An opportunity for public health education to impact outcomes. Adult Urology. 2005; 66: 606-609. PMid: 16140087. https : //doi.org/10.1016/j.urology.2005.03.069

[23] American Cancer Society. Testicular self-exam. Accessed at 2014. Available from: http://www.Cancer.Org/cancer/testicul arcancer/moreinformation/doihavetesticularcancer/d o-i-havetesticular-cancer-self-exam

[24] Singapore Cancer Society. Testicular cancer. Accessed at 2014. Available from: http://sg.movember.com/mens-health/testic ular-cancer

[25] Huyghe C, Matsuda N, Thonneau W. Physical Examination and Health Assessment. 2nd ed. Philadelphia, W.B Saunders. 2013; 788 789.

[26] John T. How to Prevent Testicular Cancer. 2018; 1: 2. Available from: https://www.Breastcancer.org/blog-posts/how-t o-prevent-testicular-cancer

[27] Etita R, Olaide E, Mombel M, et al. Knowledge, attitude and practice of testicular self-examination among male undergraduate students in a tertiary institution in Calabar, Cross River State Nigeria. Journal of Nursing and Health Science. 2017; 6(3): 48-54. https://doi.org/10.9790/1959-0603024854

[28] Valan A. A study to assess the effectiveness of information education communication package on knowledge and attitude regarding testicular cancer and testicular self-examination among students in a 
selected college at Nagercoil. Journal of Nursing and Health Science. 2016: 5(6): 19-23.

[29] Lodyga M. The relationship between health belief model constructs and factors influencing cancer self-examinations in college students, partial fulfillment of the requirements for the doctor of philosophy degree in education, Department of health education and recreation in the graduate school southern illinois University Carbondale. 2013; 6: 7.

[30] Abd El-Hay S, El Mezayen S. Knowledge and Perceptions Related to Hypertension, Lifestyle Behavior Modifications and Challenges That Facing Hypertensive Patients. IOSR Journal of Nursing and Health Science. 2015; 4(6): 15-26.

[31] Agorye J, Beatrice O, Grace-Jane E. Awareness and Practice of Testicular Self Examination among Male Medical Students of University Of Nigeria Enugu Campus South-East Nigeria. Journal of Nursing and Health Science. 2016; 5(3): 19-24.

[32] Onyiriuka N, Imoebe E. Testicular-self-examination among Nigerian adolescent secondary school boys: knowledge, attitudes and practices. Prev. Med. Hyg. 2013; 54: 163-166.

[33] Abd El-Hay S, Mohamed N. Effect of Educational Program about Breast Cancer Knowledge and Breast Self-Examination Training on Building Accurate Information and Behavior among Women. Journal of Natural Sciences Research. 2015; 5(4): 58-70.

[34] Bray L, Richiardi A, Ekbom E, eta 1. Trends in testicular cancer incidence and mortality in 22 European countries: Continuing increases in incidence and declines in mortality. International Journal of Cancer. 2006; 118(12): 3099-111. PMid: 16395710. https://doi.org/10.1002/ijc. 21747

[35] Güleser N, Unalan D. The knowledge, attitude and behaviors of health services vocational students on testicular cancer and testicular self-examination. European Journal of Oncology Nursing. 2010; 14(1): 3. https://doi.org/10.1016/S1462-3889(10) 70106 $-\mathrm{X}$

[36] Rosenstock M. Historical origins of the health belief model. Health Education Monogr. 1974; 2(1): 1-8. https ://doi.org/10.1177/ 109019817400200403

[37] Janz N, Becker H. The health belief model: a decade later. Health Education Quality. 1984; 11(1): 1-47. PMid: 6392204. https: //doi.org/10.1177/109019818401100101

[38] Avci I, Altinel B. The Validity and Reliability of Health Belief Scale for Testicular Cancer, Self-Examination. American Journal of Men's Health. 2015; 45. PMid: 26483292. https ://doi .org/10.1177/ 1557988315611226

[39] McClenahan C, Shevlin M, Adamson G, et al. Testicular selfexamination: a test of the health belief model and the theory of planned behavior, Health Education Research. 2007; 22(2): 272-273. PMid: 16885203. https://doi.org/10.1093/her/cyl076

[40] Gozum S, Capik C. A guide in the development of health behaviors: Health belief model (HBM). Dokuz Eylül Universitesi Hemşirelik Yüksekokulu Elektronik Dergisi. 2014; 7: 230-237.

[41] Miliaras D. Adult type granulosa cell tumor: a very rare case of sex-cord tumor of the testis with review of the literature. Case Rep Pathol. 2013. PMid: 23762714. https ://doi.org/10.1155/20 $13 / 932086$

[42] Zhang M. Testicular fibrothecoma: a morphologic and immunohistochemical study of 16 cases. Am Journal Surg. Pathol. 2013. 37: 1208. PMid: 23715159. https://doi.org/10.1097/PAS.0b01 3e318286c129

[43] Ulbright T. Gonadoblastoma and selected other aspects of gonadal pathology in young patients with disorders of sex development. Semin Diagn Pathol. 2014; 31: 427. PMid: 25129544. https: //doi.org/10.1053/j.semdp.2014.07.001
[44] Albers P, Albrecht W, Algaba F, et al. Cohn-Cedermark G. Fizazi K. Horwich A. Laguna M. Nicolai N. and Oldenburg J. Guidelines on Testicular Cancer: 2015 Update. European Urology. 2015; 68 : 1054-1068. PMid: 26297604. https://doi.org/10.1016/j.eu ruro.2015.07.044

[45] Elsaie OM, Elazazy H, Abdelhaie S. The Effect of Chemotherapy on Quality Of Life of Colorectal Cancer Patients before and 21 Days after the First Chemotherapeutic Sessions. Life Science Journal. 2012; 9(4): 3505.

[46] Ramim T, Mousavi Q, Rosatmnia L, et al. Student knowledge of Testicular cancer and self-examination in a medical sciences University in Iran, Basic \& Clinical Cancer Research. 2014; 6(3): 7-11.

[47] Pour H, Kunter D, Norouzzadeh R, et al. The Effect of Testicular SelfExamination Education on Knowledge, Performance, and Health Beliefs of Turkish Men. J Canc Educ. 2018; 33: 398-403. PMid: 27815814. https://doi.org/10.1007/s13187-016-1132-0

[48] Onyiriuka N, Imoebe E. Testicular self-examination among Nigerian adolescent secondary school boys; knowledge, attitudes and practices. 2013. Available from: https://www.researchgatenet/public ation/15750775

[49] Ugboma H, Aburoma H. Public awareness of testicular cancer and testicular self-examination in academic environments: a lost opportunity. Clinics. 2011; 66(7): 1125-1128.

[50] Kuzgunbay B, Yaycioglu O, Soyupak B, et al. Turkish Study Group of Public Awareness in Testicular Cancer. Public awareness of testicular cancer and self-examination in Turkey: a multicenter study of Turkish Urooncology Society. Urol Oncol. 2013; 31(3): 38691. PMid: 21429771. https://doi.org/10.1016/j.urolonc. 2011.01 .020

[51] Mohamadloo A, Mohamadloo F. Implementation of the theory of planned behavior to testicular self-examination among young men in Tehran. Social Determinants of Health. 2017; 3(1): 9-14.

[52] Akar S, Bebiş H. Evaluation of the effectiveness of testicular cancer and testicular self-examination training for patient care personnel: intervention study. Health Educ. Res. 2014; 29(6): 966-76. PMid: 25248831. https://doi.org/10.1093/her/cyu055

[53] Avci I, Kumcagiz H, Altinel B, et al. Turkish female academician selfesteem and health beliefs for breast cancer screening. Asian Pacific Journal of Cancer Prevention. 2014; 15: 155-160. PMid: 24528018. https://doi.org/10.7314/APJCP. 2014.15.1.155

[54] Muliira K, Nalwanga B, Muliira S, et al. Knowledge, perceived risk and barriers to testicular self-examination among male university students in Uganda. Journal of Mens Health. 2012; 9(1): 36-44. https://doi.org/10.1016/j.jomh.2011.11.004

[55] Peltzer K, Pengpid S. Knowledge, attitudes and practice of Testicular self-examination among male university students from Bangladesh, Madagascar, Singapore, South Africa and Turkey. Asian Pacific Journal of Cancer Prevention. 2014; 66. PMid: 26107234. https: //doi.org/10.7314/APJCP. 2015.16.11.4741

[56] Taymoori P, Berry T. The validity and reliability of champion's health belief model scale for breast cancer screening behaviors among Iranian women. Cancer Nurs. 2009; 32(6): 465-472. PMid: 19816165. https://doi.org/10.1097/NCC.0b013e3181aaf124

[57] Brown G, Patrician A, Brosch R. Increasing testicular selfexamination in active duty soldiers: an intervention study. Medsurg Nurs. 2012; 21: 97-104.

[58] Ingwu A, Shaeri B, Ezeude G. Awareness and practice of Testicular self-examination among male medical students of University of Nigeria Enugu campus, South-East Nigeria. IOSR Journal of Nursing and Health Science. 2016; 5(3).

[59] Hables R. Female University Students' Health Beliefs Regarding tsaer B Cancer Early Detection Screening Measurements. Journal of Nursing and Health Science (IOSR-JNHS). 2017; 6(3): 84-90. 